\title{
Preventive Oral Health Behaviors among African-Americans and Whites in Detroit
}

\author{
David L. Ronis, PhD; W. Paul Lang, DDS, MPH; Cathy L. Antonakos, PhD; Wenche S. Borgnakke, DDS, PhD
}

\begin{abstract}
Objective: This study compared the preventive oral health behaviors of African-Americans and whites. Methods: Face-to-face interviews were conducted with a probability sample of 384 African-American and 358 white adults living in the greater Detroit area. Questions focused on brushing, flossing, and dental visits. Results: More than 95 percent of both groups reported brushing daily; however, whites were more likely to brush all teeth, including parts that do not show. Frequency of flossing did not differ between groups. African-Americans, however, were less likely to floss all of their teeth. Whites were more likely than African-Americans to get dental check-ups at least once a year and much less likely to indicate they had never had a dental check-up. African-Americans tended to have less education and lower family income than whites and were more likely than whites to have Medicaid. Race differences in brushing thoroughness and annual check-ups were greatly reduced when income, education, and insurance were controlled statistically. Conclusions: African-Americans are less likely than whites to brush thoroughly, floss thoroughly, and get dental check-ups. These differences are partly traceable to differences in socioeconomic status and access to professional oral health care. [J Public Health Dent 1998;58(3):234-40]
\end{abstract}

Key Words: preventive dental behavior, African-Americans, whites, dental selfcare, plaque control, oral health education, health services accessibility.

Oral health authorities recommend that adults thoroughly brush and floss their teeth at least once a day and have regular dental check-ups to prevent and to obtain timely treatment for oral health problems $(1,2)$. Oral health and adherence to these recommendations in the United States have greatly improved over the past half century; nevertheless, some of the recommendations are followed only by a minority $(3,4)$. In addition, some subgroups within the population such as AfricanAmericans remain at high risk for dental diseases and may be less likely to practice preventive oral health behaviors. At 12 percent, African-Americans are the largest minority group in the United States (5); however, little is known about their oral health and oral health care behaviors. Past studies generally have found that AfricanAmericans have worse oral heal th and receive less professional oral health care than white Americans (6-12). Several studies found African-Americans to have more plaque and calculus than whites $(13,14)$. The studies comparing oral self-care of African-Americans and whites found little if any difference in frequency of oral self-care behaviors $(15,16)$. Some probability sample studies that assessed self-care behaviors had too few African-Americans for separate analysis $(3,17)$. In addition, most of the studies with adequate samples of African-Americans did not assess self-care behaviors. To our knowledge, no study has compared the thoroughness of oral selfcare behaviors of African-Americans and whites.

The purposes of the current study are (1) to provide a contemporary comparison of the preventive oral health behaviors of African-Ameri- cans and whites living in the Detroit tricounty area, including information about the thoroughness of brushing and flossing; (2) to identify demographic and socioeconomic variables that predict preventive oral health behaviors and might help to understand differences in oral health behaviors between African-Americans and whites; and (3) to identify demographic and socioeconomic subgroups least likely to perform preventive oral health behaviors. Besides helping to describe and understand the preventive oral health behaviors of African-Americans and whites, the findings may be helpful for targeting interventions to groups that most need them.

Based on past studies $(7,9,15,16)$, we hypothesize that (1) there will be at most slight race differences in the frequency of brushing and flossing, (2) African-Americans will get dental check-ups less often than whites, (3) check-ups will be strongly associated with dental insurance and socioeconomic status (SES), and (4) the relationship between race and dental check-ups will be greatly reduced when SES and dental insurance are controlled statistically. In light of the absence of past research, we had no hypotheses about race differences in thoroughness of brushing or flossing.

\section{Methods}

The study uses results from a disproportionate probability sample survey of adults 18 years of age or older living in housing units (e.g., apartments, single-family houses) in the Detroit tricounty area. Sampling was done using stratified, clustered, area probability sampling techniques based on census tracts. To maximize the ability to compare African-Americans with whites and to separate the effects of race/ethnicity from SES, the

Send correspondence and reprint requests to Dr. Ronis, Room 4247, School of Nursing, University of Michigan, Ann Arbor, MI 48109-0482. E-mail: dronis@umich.edu. Dr. Ronis is with the University of Michigan School of Nursing and Institute for Social Research and with the US Department of Veterans Affairs. Drs. Lang and Borgnakke are with the School of Dentistry, and Dr. Antonakos is with the Institute for Social Research and School of Nursing, all at the University of Michigan. Supported by NIDR grant DE10145 to W. Paul Lang and David L. Ronis. Manuscript received: 4/22/96; returned to authors for revision: 8/23/96; accepted for publication: 5/27/98. 
sampling design was disproportionate, with African-Americans oversampled and African-Americans in higher income census tracts further oversampled. One randomly selected adult was interviewed in each housing unit. Weights based on the sampling design corrected for the disproportionate sampling; hence, weighted results are representative of adults living in the greater Detroit area.

Data were collected by face-to-face interviews conducted from May to September 1994. Interviews were conducted by 31 professional interviewers from the Survey Research Center of the University of Michigan Institute for Social Research. Questions from the written questionnaire were asked verbatim by the interviewers. The overall response rate was 71 percent and 787 interviews were completed. Analyses in this paper were limited to the 384 non-Hispanic African-Americans and 358 non-Hispanic whites in the sample, a total of 742 cases.

All variables other than sex were assessed by self-report. The survey questionnaire was developed by the authors and staff of the Survey Research Center. Question wording was guided by past research and theory and by concerns expressed and terminology used in eight focus groups. The questionnaire was refined based on feedback from three rounds of pilot interviews and comments from consultants. Responses for each variable were coded into two to four categories for the current analyses.

Oral Health Behaviors. Only dentate subjects were asked questions about and included in analyses of brushing and flossing. Brushing and flossing frequency were each assessed by a single question: "In general, how often did you (brush) (floss) your teeth during the past year?" For the current analyses, the answers were coded 1 if the person took the action at least once a day and 0 if less. Thoroughness of brushing was assessed by two questions: "Do you brush all of your teeth or do you usually miss some of them?" and "Do you usually brush the parts of the teeth that don't show when you smile?" For the analyses, the answers to these questions were combined into a single dichotomous variable scored 1 if the person reported brushing all teeth including the parts that don't show, and 0 otherwise.

Thoroughness of flossing was as- sessed by the question, "When you floss, do you usually floss all of your teeth, most of your teeth, about half of your teeth, or just one or two teeth?" In the analyses, answers were coded 1 if the person reported flossing all of their teeth, and 0 otherwise. Dental check-ups were defined for the subjects as "... visits to a dental office, clinic, or other source of dental care made not because of any dental problem." Two questions were asked to assess frequency of dental check-ups. The first asked, "Have you ever gotten a dental check-up?" For subjects who said yes, a follow-up question asked, "During the past five years, how often have you had dental check-ups?" For most of the analyses, information from these questions was recoded into one dichotomous variable coded 1 if the person reported getting check-ups at least once a year and 0 otherwise, and a second dichotomous variable coded 1 if the person ever had a dental checkup and 0 if never.

Race and Other Predictor Variables. Only non-Hispanic whites and non-Hispanic African-Americans are included in the analyses. Hispanic ethnicity was determined from the question, "Do you consider yourself Hispanic or Latino?" Race was determined from the question, "Do you consider yourself primarily white or Caucasian, black or African-American, Asian or Pacific Islander, or American Indian, Eskimo, or Aleut?" Sex was assessed by interviewer observation. Age was determined from self-reported birth date. Education was assessed by the question, "What is the highest grade of school or year of college you completed?"
Family income in dollars for the previous completed year was assessed by the question, "What was (your/your family's) total combined income in 1993 before taxes, including salaries, wages, pensions, dividends, interest, and all other income?" Subjects who did not respond to this question were asked, "Was (your/your family's) total income in $1993 \$ 20,000$ or above?" Unless subjects did not know or refused to answer, they were then asked a series of up to seven dichotomous questions that together placed their family income into categories. Most subjects ( $n=519$ of 787 ) gave their income directly in dollars; about half of the others $(n=136)$ answered the dichotomous questions; the remaining subjects ( $n=132$ ) did not provide income data. Dental insurance coverage was assessed by the combination of two questions, "Do you have any kind of dental insurance?" and for subjects with such insurance, "Is your dental insurance Medicaid, or is it Blue CrossBlue Shield, or Delta Dental, or is it some other plan, or do you have more than one dental plan?" Answers to these two questions were combined into a single three-category variable: no insurance was coded 1, Medicaid insurance only was coded 2 , and other (i.e., non-Medicaid) insurance (including multiple coverage) was coded 3. Dentate status was coded 1 for subjects with teeth and 0 for edentulous subjects.

Analyses. Relationships among variables were tested by chi-square tests of association and by bivariate and multivariate logistic regression, with significance level set at .05. All analyses were conducted using

TABLE 1

Dental Behaviors of African-Americans and Whites (Weighted Data)

\begin{tabular}{|c|c|c|c|c|}
\hline Behaviors & $\begin{array}{l}\text { Number } \\
\text { of Persons }\end{array}$ & $\begin{array}{l}\text { \% African- } \\
\text { Americans }\end{array}$ & $\begin{array}{c}\% \\
\text { Whites }\end{array}$ & $\begin{array}{c}P- \\
\text { value }^{*}\end{array}$ \\
\hline Brush at least once/day & 678 & 96.7 & 96.1 & .666 \\
\hline Brush thoroughly & 676 & 85.2 & 91.9 & .025 \\
\hline Floss at least once/day & 678 & 35.0 & 32.3 & .482 \\
\hline Floss all teeth & 596 & 47.4 & 64.4 & $<.001$ \\
\hline Check-up frequency & 730 & & & $<.001$ \\
\hline Never & & 13.2 & 1.3 & \\
\hline Less than once/year & & 29.2 & 25.8 & \\
\hline At least once/year & & 57.6 & 72.9 & \\
\hline
\end{tabular}

*Chi-square test. 
weights in SUDAAN, to obtain appropriate confidence intervals and significance tests in light of the complex sampling design.

Results

Respondents. Demographic characteristics of the sample are similar to results from the 1990 US Census for the Detroit tricounty area (5), suggesting the sample is representative of the population (data available from the authors).

Preliminary Race Comparisons. Table 1 compares African-American and white subjects on preventive oral health behaviors. African-Americans and whites did not differ on frequency of brushing or flossing, with over 95 percent of each group brushing daily and about one-third of each group flossing daily. African-Americans were significantly less likely than whites, however, to brush their teeth thoroughly, to floss all their teeth, and to get dental check-ups at least once a year. A much higher proportion of African-Americans than whites had never had a dental check-up. The focus of the further analyses is on examining demographic, socioeconomic, and other variables that may predict these behaviors and provide insight into these differences in oral health behaviors between African-Americans and whites.

Chi-square tests of association were conducted using SUDAAN to compare whites and African-Americans on background characteristics. Among these variables, AfricanAmericans and whites were equally likely to be edentulous ( $7 \%$ ), and had similar age and sexdistributions; however, they differed significantly on education, income, and type of dental insurance. African-Americans generally had lower education and income than whites. For example, 20 percent of African-Americans and 10 percent of whites reported less than 12 years of education, while 37 percent of AfricanAmericans and 16 percent of whites reported family incomes below $\$ 20,000$. African-Americans were much more likely than whites (13\% vs $2 \%$ ) to depend on Medicaid for dental insurance. (Detailed data are available from the authors.) Thus, race differences in preventive oral health behaviors in this sample may be due to differences in education, income, or insurance.

Bivariate and Multivariate Analyses Predicting Each Dental Behavior. Tables 2 through 4 present the bivariate and multivariate relationships for brushing thoroughness, annual checkups, and ever having a check-up. The left sides of these tables describe the bivariate relationships between each behavior and each predictor by show-

TABLE 2

Associations Between Brushing Thoroughness and Predictor Variables (Weighted Data $n=572$ )

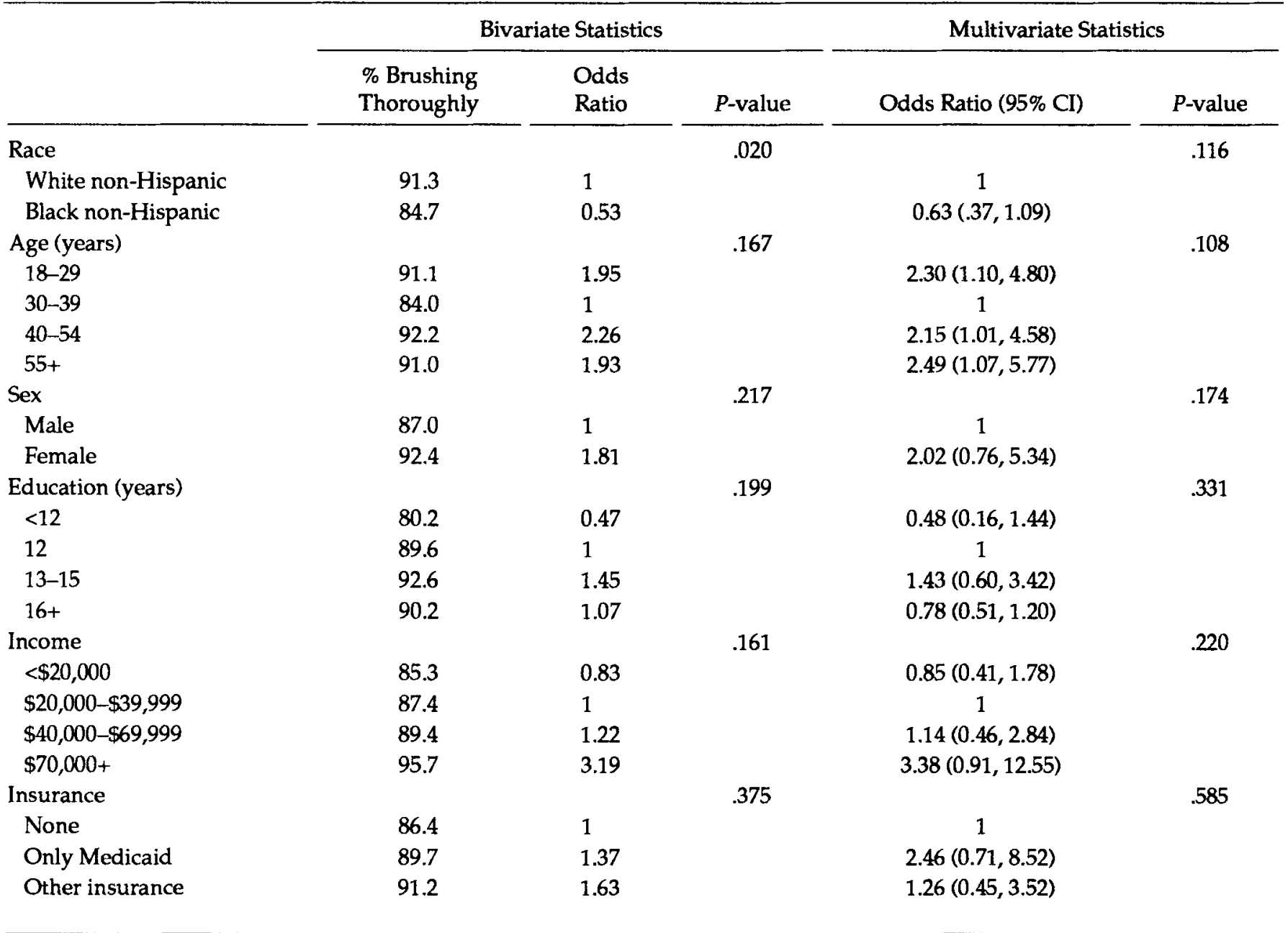


ing the percent of persons in each subgroup performing the behavior, the odds ratios from logistic regressions predicting the behavior from each predictor separately, and the $P$-values from these regressions. Each predictor was coded into one or more dummy variables. The odds ratio of 1 indicates the reference category to which the other categories are compared. Percentages and odds ratios from the bivariate logistic regressions are shown to clarify the interpretation of odds ratios and to help identify target groups for interventions.

The right sides of Tables 2 through 4 describe the multivariate relationship of each behavior to the predictors by presenting the $P$-values from the multiple logistic regressions predicting the behavior from all predictors, the odds ratios from these regressions, and confidence intervals for the odds ratios. The multivariate logistic regressions characterize the relationships when all other predictors are controlled statistically.

Brushing. African-Americans and whites were about equally likely to report daily brushing (Table 1), so detailed results from the logistic regression analyses for brushing frequency are not displayed. Brushing frequency had a statistically significant relationship with sex only. Women were more likely than men to brush their teeth at least once a day.

Brushing thoroughness had a statistically significant relationship with race, but not with other variables, in the bivariate analysis (Table 2). African-Americans were less likely than whites to brush thoroughly, with 84.7 percent of African-Americans and 91.3 percent of whites reporting thorough brushing. In the multivariate analysis, none of the predictors of brushing thoroughness were statistically significant. In an additional multiple logistic regression model not tabled, race was a significant predictor of brushing thoroughness $(P=.026)$ when education and income were not controlled.

Flossing. Whites and AfricanAmericans were about equally likely to report daily flossing (Table 1), so detailed results are not displayed. Only sex had a statistically significant relationship with flossing frequency. Women were almost twice as likely as men $(40.2 \%$ vs $23.1 \%$ ) to floss at least once a day. Flossing thoroughness had

TABLE 3

Associations Between Annual Check-ups and Predictor Variables (Weighted Data $n=616$ )

\begin{tabular}{|c|c|c|c|c|c|}
\hline & \multicolumn{3}{|c|}{ Bivariate Statistics } & \multicolumn{2}{|c|}{ Multivariate Statistics } \\
\hline & $\begin{array}{c}\text { \% Getting Annual } \\
\text { Check-ups }\end{array}$ & $\begin{array}{l}\text { Odds } \\
\text { Ratio }\end{array}$ & $P$-value & Odds Ratio (95\% CI) & $P$-value \\
\hline Race & & & .034 & & .206 \\
\hline White non-Hispanic & 71.9 & 1 & & 1 & \\
\hline Black non-Hispanic & 57.9 & 0.54 & & $0.72(0.44,1.18)$ & \\
\hline Age (years) & & & .051 & & .606 \\
\hline $18-29$ & 65.3 & 0.89 & & $1.28(0.75,2.19)$ & \\
\hline $30-39$ & 67.9 & 1 & & 1 & \\
\hline $40-54$ & 79.3 & 1.81 & & $1.51(0.84,2.73)$ & \\
\hline $55+$ & 58.8 & 0.68 & & $1.42(0.87,2.32)$ & \\
\hline Sex & & & .958 & & .102 \\
\hline Male & 68.7 & 1 & & 1 & \\
\hline Female & 68.5 & 0.99 & & $1.53(0.94,2.49)$ & \\
\hline Education (years) & & & .027 & & .775 \\
\hline$<12$ & 43.6 & 0.45 & & $0.91(0.36,2.29)$ & \\
\hline 12 & 63.1 & 1 & & 1 & \\
\hline $13-15$ & 73.5 & 1.63 & & $1.35(0.78,2.36)$ & \\
\hline $16+$ & 80.8 & 2.46 & & $1.26(0.54,2.93)$ & \\
\hline Income & & & .001 & & .036 \\
\hline$<\$ 20,000$ & 39.3 & 0.37 & & $0.48(0.28,0.80)$ & \\
\hline$\$ 20,000-\$ 39,999$ & 63.7 & 1 & & 1 & \\
\hline$\$ 40,000-\$ 69,999$ & 75.5 & 1.76 & & $1.43(0.64,3.21)$ & \\
\hline$\$ 70,000_{+}$ & 89.6 & 4.93 & & $4.04(1.29,12.70)$ & \\
\hline Insurance & & & $<.001$ & & .101 \\
\hline None & 53.9 & 1 & & 1 & \\
\hline Only Medicaid & 41.0 & 0.59 & & $1.31(0.50,3.42)$ & \\
\hline Other insurance & 76.8 & 2.84 & & $1.88(1.11,3.18)$ & \\
\hline Dentate status & & & $<.001$ & & .002 \\
\hline Dentate & 71.8 & 1 & & 1 & \\
\hline Edentulous & 25.1 & 0.13 & & $0.12(0.04,0.37)$ & \\
\hline
\end{tabular}


a statistically significant relationship with race $(P<.001)$, but not with other variables (all $P$ S $>.1$ ), in both the bivariate and multivariate analyses (not tabled). About two out of three whites reported flossing thoroughly (i.e., all of their teeth), while fewer than half of the African-Americans reported flossing thoroughly.

Check-ups. Annual check-up frequency had statistically significant bivariate relationships with race, education, income, insurance, and dentate status (Table 3 ). Whites were more likely than African-Americans to get at least one check-up a year. The likelihood of annual check-ups increased with increasing education and income. Respondents with Medicaid insurance were least likely to get annual check-ups. Dentate respondents were much more likely to get annual checkups than edentulous respondents.

In the multivariate analysis, only income and dentate status were significant predictors of annual check-ups. Thus, controlling for the influence of other predictors, race, education, and insurance became nonsignificant in the multivariate analysis. In an additional multiple logistic regression model dropping education and income, race was statistically significant $(P=.046)$.

The relationships of ever having had a check-up with race, age, education, income, and insurance were statistically significant in the bivariate analysis (Table 4). Whites were more likely than African-Americans to have had a check-up. Respondents in the 40-54-year-old age category were most likely to have had a check-up, and respondents in the 55-year-oid and older age category were least likely to have ever had a check-up. The likelihood of having had a check-up increased with increasing education and income. Respondents with Medicaid insurance were least likely to have had a check-up. In the multivariate analysis, race, age, sex, and insurance had statistically significant relationships with ever having had a check-up.

\section{Discussion}

Using a nonexperimental cross-sectional design, this study does not provide evidence about the directions of

TABLE 4

Associations Between Ever Having a Check-up and Predictor Variables (Weighted Data $n=616$ )

\begin{tabular}{|c|c|c|c|c|c|}
\hline & \multicolumn{3}{|c|}{ Bivariate Statistics } & \multicolumn{2}{|c|}{ Multivariate Statistics } \\
\hline & $\begin{array}{c}\text { \% Ever Had } \\
\text { Check-up }\end{array}$ & $\begin{array}{l}\text { Odds } \\
\text { Ratio }\end{array}$ & $P$-value & Odds Ratio (95\% CI) & $P$-value \\
\hline Race & & & $<.001$ & & $<.001$ \\
\hline White non-Hispanic & 98.5 & 1 & & 1 & \\
\hline Black non-Hispanic & 87.3 & 0.10 & & $0.15(0.06,0.38)$ & \\
\hline Age (years) & & & $<.001$ & & .012 \\
\hline $18-29$ & 97.3 & 1.41 & & $2.50(0.64,9.87)$ & \\
\hline $30-39$ & 96.2 & 1 & & 1 & \\
\hline $40-54$ & 99.0 & 4.03 & & $2.28(0.82,6.35)$ & \\
\hline $55+$ & 90.6 & 0.39 & & $0.24(0.12,0.48)$ & \\
\hline Sex & & & .760 & & .018 \\
\hline Male & 95.7 & 1 & & 1 & \\
\hline Female & 96.1 & 1.09 & & $2.54(1.26,5.11)$ & \\
\hline Education (years) & & & .029 & & .846 \\
\hline$<12$ & 87.7 & 0.39 & & $1.28(0.52,3.17)$ & \\
\hline 12 & 94.8 & 1 & & 1 & \\
\hline $13-15$ & 98.0 & 2.70 & & $1.73(0.56,5.34)$ & \\
\hline $16+$ & 98.5 & 3.65 & & $1.14(0.21,6.30)$ & \\
\hline Income & & & $<.001$ & & .204 \\
\hline$<\$ 20,000$ & 87.7 & 0.24 & & $0.50(0.23,1.07)$ & \\
\hline$\$ 20,000-\$ 39,999$ & 96.7 & 1 & & 1 & \\
\hline$\$ 40,000-\$ 69,999$ & 97.7 & 1.41 & & $0.96(0.31,3.00)$ & \\
\hline$\$ 70,000+$ & 99.9 & 28.46 & & $13.06(1.26,135.56)$ & \\
\hline Insurance & & & $<.001$ & & .009 \\
\hline None & 96.2 & 1 & & 1 & \\
\hline Only Medicaid & 70.1 & 0.09 & & $0.10(0.02,0.43)$ & \\
\hline Other insurance & 97.7 & 1.68 & & $1.13(0.47,2.73)$ & \\
\hline Dentate status & & & .079 & & .983 \\
\hline Dentate & 96.2 & 1 & & 1 & \\
\hline Edentulous & 91.6 & 0.43 & & $1.01(0.34,3.06)$ & \\
\hline
\end{tabular}


causal relationships. All variables except sex were assessed by self-report and may be subject to measurement error due to communication difficulties, memory errors, and self-presentation tactics. The careful construction of the questionnaire using focus groups and extensive pilot testing reduces this potential problem. A previous study using very similar questions found that self-report of daily flossing and annual check-ups predicted plaque, calculus, gingivitis, and periodontal destruction $(11,12)$ - findings that also contribute to confidence in the measures used in this study.

Bivariate Comparisons of Oral Health Behaviors of African-Americans and Whites. The first goal of the study was to compare the preventive oral health behaviors of AfricanAmericans and whites. In light of past studies $(7,9,15,16)$, we hypothesized that African-Americans and whites would be very similar in frequency of brushing and flossing, but that African-Americans would have dental check-ups less frequently than whites. These hypotheses were supported. Although no hypotheses were proposed about thoroughness (because no previous studies compared AfricanAmericans and whites on thoroughness), the bivariate analyses found clear race differences on these variables, with African-Americans less likely than whites to brush and floss thoroughly.

Identifying Predictors of Oral Health Behaviors/Understanding the Differences. The second goal was to identify predictors of oral health behaviors other than race, and to determine whether race differences in oral health behaviors would be reduced or eliminated when these predictors were statistically controlled. If so, the race differences found in the bivariate analyses might be in terpreted as being due to these other variables, rather than being due to race per se. Based on past studies $(7,9,15,16)$, we hypothesized that dental insurance and socioeconomic status, indicated by education and income, would be strongly associated with dental check-ups and that the relationship between race and check-ups would be greatly reduced when SES and insurance were statistically controlled. When check-up frequency was coded as at least once a year versus less than once a year, these hypotheses were supported. Race dif- ferences became nonsignificant, while income remained significant when insurance and SES were controlled.

When check-up frequency was coded as ever versus never having a check-up, the hypothesis that race differences would be reduced when insurance and SES were controlled was not supported. The race difference in ever having a check-up remained strong and statistically significant. In hindsight, it is not surprising that race differences in lifetime nonuse of dental services are not "explained" by current income and insurance.

We had not proposed hypotheses about brushing and flossing thoroughness, but found race differences in bivariate analyses of these measures. Race was a significant predictor of brushing thoroughness when education and income were not controlled, but not when they were controlled in multivariate analyses. In contrast, race differences in flossing thoroughness were not notably reduced when other factors were statistically controlled.

In sum, bivariate analyses found that African-Americans were less likely than whites to brush thoroughly, floss thoroughly, ever have dental check-ups, and have annual dental check-ups. Notable parts of the race difference in annual check-ups may be due to race differences in SES and insurance, rather than to race per se. Differences in SES and insurance explained notable parts of the race differences in getting annual check-ups. In contrast, none of the tested variables were useful in interpreting the race differences in thoroughness of flossing or in ever having a dental check-up. Understanding these differences will probably require examining cultural variables such as health beliefs and norms (18-20) and may require qualitative research $(21,22)$ to explore the influences of culture and community.

Selecting Target Groups. The third goal of the study was to identify demographic and socioeconomic subgroups least likely to practice dental preventive behaviors, as potential target groups for interventions. Reviewing Tables 2 through 4 and untabled results for brushing and flossing frequency and flossing thoroughness reveals that males, low-income persons, and African-Americans were less likely than others to perform preven- tive dental behaviors. However, the subgroups least likely to carry out the actions differ from behavior to behavior. Regular and thorough brushing were least common among males and low-income persons. Regular flossing was least common among males. Thorough flossing was least common among African-Americans. Getting dental check-ups was least common among African-Americans, persons 55 years of age and older, persons with low income, and persons without private dental insurance. These findings suggest that males would be important targets for self-care behaviors, African-Americans would be important targets for interventions to increase the thoroughness of flossing, and African-Americans and persons with low income who have either Medicaid or no insurance would be important targets for interventions to increase use of professional dental services. The finding that 13 percent of AfricanAmericans reported never having had a dental check-up implies that interventions to increase frequency of preventive dental visits must not be restricted to persons who already get check-ups. Interventions must reach out to those who only use dental services for acute problems and those who never receive dental services.

\section{Acknowledgments}

We thank Judith $\mathrm{H}$. Connor and Steven $\mathrm{G}$. Heeringa of the University of Michigan Survey Research Center for work on sampling error analysis using SUDAAN.

\section{References}

1. American Dental Association. Wake up to prevention for the smile of a lifetime. J Am Dent Assoc 1988;116:3g,6g-13g.

2. National Institutes of Health. Rx for sound teeth. Washington, DC: US Government Printing Office, 1991; NIH pub no 91-3245.

3. Chen M, Rubinson L. Preventive dental behavior in families: a national survey. J Am Dent Assoc 1982;105:43-6.

4. Ronis DL, Lang WP, Farghaly MM, Ekdahl SM. Preventive oral health behaviors among Detroit-area residents. J Dent Hyg 1994;68:123-30.

5. Bureau of Census. 1990 Census of population and housing: summary population and housing characteristics. Washington, DC: Bureau of the Census, 1991.

6. Beck JD, Koch GG. Characteristics of older adults experiencing periodontal attachment loss as gingival recession of probing depth. J Periodont Res 1994;29: 290-8.

7. Bloom B, Gift HC, Jack SS. Dental services and oral health: United States, 1989. Hyattsville, MD: National Center for 
Health Statistics, 1992; DHHS pub no (PHS) 93-1511 (Vital Health Statistics, series 10 , no 183 )

8. Brown LF, Beck JD, Rozier RG. Incidence of attachment loss in community-dwelling older adults. I Periodontol 1994;65: 316-23.

9. Hunt N, Silverman HA. Use of dental services in 1980. Health Care Financ Rev 1987:9:31-42.

10. Jack SS, Bloom B. Use of dental services and dental health: United States, 1986. Hyattsville, MD: National Center for Health Statistics, 1988; DHHS pub no (PHS) 88-1593 (Vital Health Statistics, series 10, no 165).

11. Lang WP, Farghaly MM, Ronis DL. The relation of preventive dental behaviors to periodontal health status. J Clin Periodontol 1994:21:194-8.

12. Lang WP, Ronis DL, Farghaly MM. Preventive behaviors as correlates of periodontal health status. J Public Health
Dent 1995;55:10-17.

13. Kelly JE, Harvey CR. Basic data on dental examination findings of persons 1-74 years, United States, 1971-1974. Hyattsville, MD: National Center for Health Statistics, 1979; DHEW pub no (PHS) 791662 (Vital Health Statistics, series 11, no 214).

14. Hughes JT, Rozier RG, Ramsey DL. Natural history of dental diseases in North Carolina. Durham, NC: Carolina Academic Press; 1982.

15. Ronis DL, Lang WP, Farghaly MM, Passow E. Toothbrushing, flossing, and preventive dental visits by Detroit-area residents in relation to demographic and socioeconomic factors. J Public Health Dent 1993;53:138-45.

16. Swank ME, Vernon SW, Lairson DR. Patterns of preventive dental behaviors. Public Health Rep 1986;101:175-84.

17. Craig TT, Montague JL. Family oral health survey. J Am Dent Assoc 1976;
92:326-32.

18. Chen MS, Land KC. Testing the health belief model: LISREL analysis of alternative models of causal relationships be tween health beliefs and preventive dental behavior. Soc Psychol Q 1986;49:4560.

19. McCaul KD, Glasgow RE, Gustafson C. Predicting levels of preventive dental behaviors. ] Am Dent Assoc 1985;111:601-5.

20. Ronis DL, Antonakos CL, Lang WP. Usefulness of multiple equations for predicting preventive oral health behaviors. Health Educ Q 1996:23:512-27.

21. Kleinman A. Patients and healers in the context of culture: an exploration of the borderland between anthropology, medicine, and psychiatry. Berkeley, CA: University of California Press, 1980.

22. Nettleton S. Understanding dental health beliefs: an introduction to ethnography. Br Dent J 1986;161:145-7. 